\title{
ELEMENT CHTONICZNY W BUŁGARSKIEJ OBRZĘDOWOŚCI CYKLU WIOSENNEGO
}

\author{
JoAnNA MLECZKO \\ University of Silesia in Katowice
}

\begin{abstract}
CHTHONIC ELEMENTS IN BULGARIAN SPRING CYCLE RITES. The paper analyzes Bulgarian spring rites of scaring away insects, reptiles, predators and rodents, as well as magical prohibitions and acts protecting against them (symbolic closing off, sewing off, blocking off animal snouts / eyes). Interpreting a rite as a cultural text, particular attention is drawn to the relation between the rite's ritual (the act, its performer and object, used props, placement in time and space) and verbal layers (words accompanying the action). The excerpted folklore texts (expressions pronounced during the act of scaring away) are discussed from the point of view of structural variety.
\end{abstract}

Keywords: calendar spring cycle, rite, beliefs, magic, folklore text, chthonic animals

W mitologii wczesnej wiosny szczególne miejsce zajmują wierzenia o pojawieniu się na ziemi zwierząt chtonicznych - insektów, gadów, drapieżników i gryzoni ${ }^{1}$ (Agapkina 2002: 53). Odcisnęły one wyraźne piętno na obrzędowości tego okresu, zwłaszcza u Słowian południowych. Artykuł jest próbą analizy, na podstawie bułgarskich materiałów etnograficznych i folklorystycznych, działań o charakterze katarktyczno-apotropeicznym (rytualne wypędzenie, magiczne unieszkodliwienie, zakazy), podejmowanych dla ochrony człowieka przed wrogimi siłami chtonicznymi, a jednocześnie, w planie mitycznym, prowadzących do rozdzielenia dwóch światów, by tym samym umożliwić przejście zimy w wiosnę.

1 Zob. wierzenia i legendy wskazujące na ich chtoniczne pochodzenie: wszy - pochodzą z prochu węża, którego Chrystus rzucił o ziemię, gdy ten chciał go ukąsić lub z popiołu spalonego węża, który swoim ciałem zatkał dziurę w arce Noego (Gura 1997: 416-417); gady - wyszły z ciała diabła, który pękł od zapachu kadzidła, por. też - wąż jako przeciwnik słońca (Gura 1997: 281, 283); wilk - ludowe wierzenia mówią o jego związkach z dawnym chtonicznym bóstwem lasu (Vasileva 2006b: 68), zaś w dualistycznych legendach uważany jest za twór diabła; jego mitologiczny obraz uwzględnia charakterystyczną dla istot chtonicznych asymetryczność formy - kulawy, jednonogi (Georgieva 1993: 55-56); mysz - powstała z diabła, który pękł w cerkwi od zapachu kadzidła, por. też pokrewieństwo między myszami i gadami w związku z funkcją domowego opiekuna (Gura 1997: 403-404). 


\section{INSEKTY}

W świadomości nosicieli tradycyjnej kultury najskuteczniejszą formą ochrony przed insektami jest ich rytualne wypędzenie. Ma ono miejsce podczas kliku dni świątecznych ${ }^{1}$, kiedy to pchły i wszy² są wytrzepywane z posłania, pościeli, ubrań ${ }^{3}$ (Vasileva 1974: 324; Vasileva 1985: 215; Vasileva 1993b: 187), wymiatane z nieczystościami (Vasileva 1985: 213; Raycheva-Ganeva 2002: 341, 343) i palone (Vasileva 1974: 324; Stamenova 1986: 264; Popov 1994: 101; Grebenarova 1996: 331), wyrzucane ze szmatą (Vasileva 1985: 213), miotłą ${ }^{4}$ (Vasileva 1993b: 187) albo skorupkami jajek ${ }^{5}$ (Vasileva 1985: 213; Vasileva 1993a: 245; Popov 1999: 305; Raycheva-Ganeva 2002: 341).

W wielu miejscach przeskakuje się przez płonące śmieci (Vasileva 1974: 324; Stamenova 1986: 264; Popov 1994: 101; Raycheva-Ganeva 2002:343) lub specjalnie rozpalane ognie (Vasileva 1985: 212; Stamenova 1986: 264; Vasileva 1993a: 245; Vasileva 1993b: 187; Raycheva-Ganeva 2002: 339), rzuca płonącymi pochodniami (Vasileva 1974: 320; Popov 1999: 306) i wypuszcza ogniste strzały - да се маха лошото, да няма бълхи [żeby odeszło zło, żeby nie byto pchet] (Stamenova 1986: 259).

Jako istoty chtoniczne insekty odsyłane są do tamtego świata, który na poziomie tekstu rytualnego obrzędu ${ }^{6}$ wypędzenia jest kodowany na dwa sposoby7. Obce może być w najbliższym sąsiedztwie człowieka, zaczynać się już za progiem domu, jak wtedy, gdy gospodynie lub dzieci ustawiają się po dwóch stronach jego drzwi, a następnie uderzając w nie kamyczkami, nawołują: Вън бълхи! Bъmpe Mapma! [Na zewnątrz pchty! Do środka Marta!] (Vasileva 1974: 324; Vasileva 1993b: 187)². Częściej jednak cechą jego lokalizacji jest

1 Баба Mapma / Baba Marta (1 III), Св. Четиридесет мъченици / dzień świętych czterdziestu męczenników z Sebasty (9 III), Благовещение / Zwiastowanie Pańskie (25 III), Сирна неделя / tydzień poprzedzający Wielki Post, Сирни заговезни / święto zapoczątkowujące Wielki Post, Тодорова неделя / pierwszy tydzień Wielkiego Postu, poprzedzający dzień św. Teodora z Amasei / Тодоровден.

2 W ekscerpowanych formułach słownych, które towarzyszą czynnościom rytualnym jako obiekt wypędzenia najczęściej występują pchły. Wszy lub oba insekty jednocześnie pojawiają się w nich sporadycznie.

3 Gdzieniegdzie wieczorem, w dniu zapoczątkowującym Wielki Post starzy i młodzi tańczą choro w intencji wzrostu bawełny i konopi, wierząc, że podczas tańca wytrzepują się pchły (Raycheva-Ganeva 2002: 339).

$4 \mathrm{O}$ miotle jako przedmiocie spełniającym rytualne funkcje oczyszczania i oddalania zob. Vinogradova \& Tolstaya 1993: 32 .

5 Wierzy się, że zbierają się w nich pchły - stąd pilnowanie, by podczas wieczerzy na Sirni zagovezni skorupki nie spadły na ziemię (Raycheva-Ganeva 2002: 345).

6 Obrzęd jest tu rozumiany jako tekst kultury, w którym można wyodrębnić dwa organicznie zespolone poziomy (teksty): rytualny (czynności, ich wykonawcy i adresaci, czas i przestrzeń, użyte rekwizyty) oraz werbalny (towarzyszące czynnościom słowa) - szerzej o tym zob. Tolstoy 1995: 63-67.

7 Szerzej o dwóch przeciwstawnych wyobrażeniach tamtego świata zob. Bayburin 1990: 9.

8 Zob. też miejsca, w których gospodyni kładzie na progu domu szmatę i uderzając w nią trzósłem, woła: Mарта у къщи, бъйлите навън [Marta do domu, pchty na zewnątrz] (Vasileva 1985: 215). 
tu oddalenie: 1 marca, zamiatając wszystkie izby w domu, dziewczyna upuszcza na podłogę orzech, który toczy się przed miotłą, a na końcu rzuca go gdzieś daleko, żeby nie było pcheł (Raycheva-Ganeva 2002: 343), szmata, którą w dniu zapoczątkowującym Wielki Post gospodyni wlecze za sobą, a później uderza w nią siekierą lub nożem, by wypłoszyć insekty, zostaje wyrzucona daleko od podwórza (Vasileva 1985: 213), zaś skorupki po zjadanych tego dnia jajkach - za płot, където не стъпва човешки крак [gdzie nie postała ludzka stopa] (Popov 1999: 305) albo na podwórze sąsiadów (Raycheva-Ganeva 2002: 343).

W kodzie przestrzennym obrzędu poza miejscami przynależnymi tamtemu światu znaczenia nabierają również te, które znajdują się na granicy między swoim a obcym, gdzie najłatwiej o przejście z jednej przestrzeni do drugiej ${ }^{1}$ :

- $\quad$ na podwórzu² domu pali się więc śmieci (Vasileva 1974: 324; Vasileva 1985: 212; Stamenova 1986: 264; Popov 1994: 101; Grebenarova 1996: 327), wytrzepuje pościel i posłanie, a czasami pozostawia skorupki jajek (Vasileva 1985: 213, 215);

- $\quad$ na drogę wymiatane są nieczystości z domu i obejścia (Vasileva 1993b: 187; Popov 1994: 264; Raycheva-Ganeva 2002: 341), a gdzieniegdzie także wyrzucane skorupki jajek (Vasileva 1985: 213) lub wylewana woda, w której je gotowano (RaychevaGaneva 2002: 341);

- $\quad$ w kierunku rzeki kawalerowie rzucają płonące pochodnie, за да идат там бълхите [żeby odeszły tam pchty], a kobiety wyrzucają do niej skorupki jajek i wylewają wodę, w której były gotowane (Popov 1999: 306);

- $\quad$ na skraju wsi rozpala się ognie (Vasileva 1974: 320).

O ile na poziomie tekstu rytualnego obrzędu wypędzenia insektów kategoria obcości ma przede wszystkim wymiar przestrzenny, o tyle na poziomie tekstu werbalnego jest nim wymiar personalny. W większości tekstów folkloru towarzyszących wiosennemu pozbywaniu się pcheł i wszy są one odsyłane do tych, których zwykło się łączyć ze sferą obcego lub tych, którym przyznaje się status mediatorów między obu światami. I tak obcy to w ekscerpowanym materiale przede wszystkim sąsiedzi:

- Комшийке, прибери си черните кози! [Sq̨siadko, zabierz sobie czarne kozy!] wołają, podrzucając skorupki jajek pod cudzą bramę lud do cudzego ogrodu (Popov 1994: 98);

1 Por. parametry temporalne podejmowanych działań - w cyklu rocznym przypadają w okresie przejścia jednej pory roku w drugą (zimy w wiosnę), zaś w cyklu dobowym - w momentach granicznych, wyznaczających przejście nocy w dzień / dnia w noc (świt, zmierzch).

2 O zmiennym statusie podwórza jako przestrzeni swojej, obcej lub granicznej - zob. Plotnikova 1999:31-33. 
- Яно, вър си прибери черната свиня с черните прасенца! [Jano, zabierz sobie czarną świnię z czarnymi prosiętami!] - nawołują, wypowiadając imię sąsiadki, gdy wyrzucają śmieci na drogę (Raycheva-Ganeva 2002: 341).

W obu formułach zwraca uwagę tabuizacja obiektu wypędzenia. Pojawia się on w nich pod postacią zwierząt, które uznawane są za nieczyste (koza1) (Belova 1999: 522) lub pierwotnie nieczyste (świnia) (Belova 2009: 573), a ich związek z tamtym światem, podobnie jak wszy i pcheł, dodatkowo został podkreślony przez użycie przymiotnika czarny.

W tradycyjnych społecznościach jako obcy traktowani są też przedstawiciele innych grup etnicznych i to do nich, skaczące przez ognie dzieci odsyłają insekty²: На циганите - бъхлите, на влашките - въшките! [Cyganom - pchty, Wołochom - wszy!] (Vasileva 1985: 213). Nieprzypadkowo wzmiankowani są tu właśnie Cyganie i Wołosi. Ci pierwsi w folklorze bułgarskim zwykle występują z określeniem czarni (църни) ${ }^{3}$, zaś drugim przypisuje się nieludzkie pochodzenie ${ }^{4}$ (Manova 2016: 445, 447), co jeszcze silniej łączy ich z przestrzenią kulturowo nieoswojoną.

W roli mediatora między tym i tamtym światem występuje, przywoływana w licznych formułach wypędzenia, mityczna Baba Marta ${ }^{5}$ - żeńska personifikacja marca: Бабy Марто-у, въшките и бъйлите на тебе да идат! [Babo Marto, wszy i pchty niech przejda na ciebie!] - wołają, skacząc przez ogień, małe dzieci (Vasileva 1985: 212). Czasami, będąc już w posiadaniu insektów, staje się ona ich dysponentem, czemu daje wyraz, przenosząc je na innych ${ }^{6}$ i co nie bez znaczenia, reprezentujących lewy człon opozycji obcy - swój: Ба6o Mарто, яла си земи въшките да ги занеш на попадийката [Babo Marto, chodź, weź sobie pchty i zanieś je żoneczce popa]; Бабо Марто, яла си земи бъхлите да ги занеш на докторката [Babo Marto, chodź, weź sobie pchty i zanieś je doktorce] - nawołują dzieci i dorośli, gdy 1 marca trzykrotnie skaczą przez ogień (Raycheva-Ganeva 2002: 343).

1 Por. zagadki i inne małe gatunki folkloru, w których pchłom i wszom przypisuje się symbolikę zwierząt, najczęściej bydła (Gura 1997: 433) oraz bułgarskie wyobrażenia, w których koza funkcjonuje jako jedno z wcieleń diabła (Georgieva 1993: 62).

2 Por. poświadczone nie tylko w języku bułgarskim nazwy karalucha i niektórych innych insektów, określające je jako obcych, innoplemieńców (np. bułg. турчин-кукурчин 'pluskwa', pol. prusak, szwab, francuz 'karaluch') (Gura 1997: 434).

3 Por. kolor czarny jako jedną z podstawowych charakterystyk tamtego świata i tych, którym nadaje się status obcego (Belova 2012: 513, 515).

4 Według jednej z etiologicznych legend Wołoch miał powstać ze strużyn (Manova 2016: 447).

5 Szerzej o statusie Baby Marty - zob. Mleczko 2015: 191-20o.

6 W jednym z rejonów Bułgarii dzieci skacząc 1 marca przez ogień, wołają: да не дава Марта с кутелчетата бълхи [żeby Marta nie dawała pchet w kociołkach] (Mikov 1985: 15). 
Analogiczną, mediacyjną funkcję pełni tu również młoda mężatka, która do momentu urodzenia dziecka ma wciąż nieustabilizowany status socjalny ${ }^{1}$. Stąd poświadczone w materiale takie formuły słowne jak: Бъйлите и въшките - на младите булки [Рсhły i wszy - na młode mężatki] (Vasileva 1985: 212); Бягайте, бъхли, в булкините гащи [Uсіеkajcie pchty, w gacie młodych mężatek] (Raycheva-Ganeva 2002: 264), które dorośli i dzieci wykrzykują, skacząc przez ogień.

\section{GADY}

W obrzędowości świąt ${ }^{2}$, które tradycja ludowa łączy z pojawieniem się na ziemi gadów, obok ich rytualnego wypędzania i magicznego unieszkodliwiania, ważną rolę odgrywają powszechnie przestrzegane zakazy, u źródeł których leży z jednej strony podobieństwo nitki do wijącego się ciała węża, z drugiej - podobieństwo śladów użycia ostrych przedmiotów do tych, jakie pozostają na ciele po ukąszeniu węża i jaszczurki ${ }^{3}$. W wielu rejonach Bułgarii kobiety nie zarabiają wówczas ciasta w dzieży (Drazheva 1980: 440), че ще се свие зъмя на него [bo zwinie się na nim wąż] (Stamenova 1986: 265), nie czeszą włosów (Drazheva 1980: 440; Stamenova 1986: 264), nie dotykają nici, powrozu (Drazheva 1980: 440; Popov 1994: 101), nie szyją (Drazheva 1980: 440; Vasileva 1985: 215; Stamenova 1986: 265; Popov 1994: 101-102), nie biorą do ręki wrzeciona (Drazheva 1980: 440), nie przędą (Raycheva-Ganeva 2002: 344), nie tkają (Stamenova 1986: 264), nie robią na drutach (Drazheva 1980: 440; Popov 1994: 101-102; Raycheva-Ganeva 2002: 344). Tym samym nie wykonują niczego, co można określić czasownikiem влача 'wlec, ciągnąć, czesać, gręplować wełnę’ (Slawski 1987: t. 1: 89) i co ludowa etymologia mogłaby łączyć z gadami (влечуги).

W ramach rytualnego wypędzania gadów, podobnie jak przy pozbywaniu się insektów ${ }^{4}$, wcześnie rano, przed wschodem słońca przystępuje się do porządków i palenia śmieci (Drazheva 1980: 440; Vasileva 1985: 215; Vasileva 1993a: 248; Raycheva-Ganeva 2002: 341),

1 W życiu młodej mężatki wiosna wiąże się ze stopniowym, wyznaczanym przez udział w kolejnych świętach cyklu dorocznego, procesem włączania do nowej grupy społecznej. W tym czasie widomym znakiem jej stanu marginalnego jest wygląd, którym odróżnia się od panien i kobiet zamężnych - ozdoby, strój, nakrycie głowy pełnią funkcję ekwiwalentu dziecka i są traktowane jako zapowiedź pojawienia się, oczekiwanego po nocy poślubnej, potomstwa (Mleczko 2018: 317-318).

2 Трифоновден / dzień św. Tryfona (1 II), Баба Марта, Св. Четиридесет мъченици, Благовещение, Еремия / dzień proroka Jeremiasza (iV), Сирна неделя, Сирни заговезни, Тодорова неделя.

3 Wskazują na to ludowi informatorzy - w jednym z rejonów nie szyją, да не ги дупчат змиите [żeby nie kłuły je węże] (Stamenova 1986: 265). Por. też poświadczony w Serbii, obowiązujący kobiety w dniu św. Teodora nie zakaz, a nakaz szycia, by wykłuć oczy wężom (Tolstoy 1990: 103).

4 Por. miejsca, w których te same czynności (palenie ogni i przeskakiwanie przez nie) mają chronić zarówno przed insektami, jak i gadami (Stamenova 1986: 256, 264; Vasileva 1993b: 180), a także jedną z formut werbalnych: Бягайте, змии, гущери, бии... [Uciekajcie, węże, jaszczurki, pchty...] (Drazheva 1980: 440). 
czemu w wielu miejscach może towarzyszyć (w różnych konfiguracjach): przeskakiwanie ognia ${ }^{1}$, uderzanie w przedmioty z żelaza², obchód domu lub całego obejścia ${ }^{3}$.

Działania rytualne na ogół łączą się tu z wypowiadaniem specjalnych formuł słownych. Część z nich, na płaszczyźnie strukturalnej i semantycznej, odpowiada formule Бъъли вънка, Марта вкъщи [Pchty na zewnątrz, Marta do domu] (Stamenova 1986: 264). Charakteryzuje je wyraźnie przeciwstawienie swojego obcemu - semiotycznie różnych przestrzeni i związanych z nimi postaci. Tym samym miejsce człowieka, świętego jest w tym świecie, a sił chtonicznych - w tamtym (Agapkina 2002: 74):

- $\quad$ za progiem domu

Вкъщи Иримия, отвън змия [W domu Jeremiasz, na zewnątrz wąż] (Luleva 2002: 96);

- w miejscach, które ludowe wierzenia i wyobrażenia łączą z obecnością gadów (w ekscerpowanym materiale przede wszystkim węży);

- $\quad$ na polu ${ }^{4}$

Змии и гущери у полето, (името на човека) у село [Węże i jaszczurki na polu, (imię konkretnej osoby) we wsi] (Luleva 2002: 96);

- w lesie 5

Змиите в полето, / Аз съм в гората, / Аз съм в полето, / Змиите в гората [Wężе па polu, / Ja w lesie, / Ja na polu, / Węże w lesie] (Drazheva 1980: 400); Еремия у поле, бежте змии у гору [Jeremiasz w polu, uciekajcie węże do lasu] (Luleva 2002: 94);

- $\quad$ pod kamieniem ${ }^{6}$

Змийка7 под камък, яз на камък! Змийка под чилийка, яз на чилийка! Змийка под брягче, яз на брягче! [Wężyk pod kamienieniem, ja na kamieniu! Wężyk pod krzakiem, ja na krzaku! Wężyk pod brzeżkiem, ja na brzeżku!] (Raycheva-Ganeva 2002:341);

1 Czasami w tym celu pali się specjalne ognie (Stamenova 1986: 264; Vasileva 1993b: 180).

2 Bywa, że wypłoszeniu gadów ma służyć tylko silny szum towarzyszący uderzeniom pogrzebaczem, szczypcami do węgli czy w pokrywę do formy chlebowej (Stamenova 1986: 264; Vasileva 1993a: 248; Grebenarova 1996: 331). 3 [porządki + palenie śmieci + hałas] (Grebenarova 1996:329); [porządki + palenie śmieci + obchód] (Vasileva 1974: 325-326; Vasileva 1985: 215; Popov 1994: 101); [porządki + palenie śmieci + hałas + obchód] (Popov 1994: 101; Vasileva 1993b: 187).

4 Według średniowiecznego apokryfu Objawienie Barucha na wielkim polu, na wysokiej górze leży wąż długi od wschodu do zachodu. Por. też wierzenia o wężu - opiekunie pola (Georgieva 1993: 63, 65).

5 Por. zamówienia przeciw ukąszeniu węża, w których jest on nazywany leśnq matką / горска маŭкa (Benovska-Sabkova 1995: 45).

6 Zob. pieśń o siostrze trucicielce, która bierze jad od węża znalezionego w zielonym lesie pod kamieniem (Benovska-Sabkova 1995: 45).

7 W ekscerpowanym materiale to jedyny przykład formuły werbalnej, w której obiekt wypędzenia (wąż) został nazwany zdrobnieniem świadczącym o zastosowaniu strategii obłaskawienia. 
- $\quad$ na dole ${ }^{1}$

Евог! Азе като съм доле, / ти да си в поле, / като съм в поле, / ти да си доле! [Еwо! Kiedy ja jestem na dole, / ty bądź na polu, / kiedy ja jestem na polu, / ty bądź na dole!] (Benovska-Sabkova 1995: 22);

- $\quad$ worzu ${ }^{3}$

Еремия у полье, змия у море! [Jeremiasz w polu, wąż w morzu!] (Benovska-Sabkova 1995: 16), Бежте, змии, гущери, у море, Еремия у полье! [Uciekajcie, węże, jaszczurki do morza, Jeremiasz w polu!] (Benovska-Sabkova 1995: 16).

Jednak dla większości ekscerpowanych formuł najważniejszy jest sam akt wypędzenia. W ich strukturze jako obligatoryjny komponent występuje wezwanie gadów do ucieczki: Бягайте зъми и гущери! [Uciekajcie węże i jaszczurki!] - woła gospodyni, gdy trzykrotnie obchodzi z zapaloną szmatą dom i budynki gospodarskie (Vasileva 1974: 325). Czasami formuła imperatywu o znaczeniu 'biec, uciekać' bywa rozszerzona o wskazanie miejsca oddalenia: Бегайте, змии и гущери, през Черното море! [Uciekajcie, węże i jaszczurki, przez Morze Czarne!] (Benovska-Sabkova 1995: 16), Бягайте змии и гущери на 40 разкрача!‘ [Uciekajcie węże i jaszczurki na 40 kroków!] (Gura 1997: 342).

W wielu wariantach, zwłaszcza tych bardziej rozbudowanych, wezwaniu do ucieczki towarzyszy wyrażony eksplicytnie jej powód. Może nim być samo święto (Бежme, змии и гущери, че утре е Благовец! [Uciekajcie, węże i jaszczurki, bo jutro jest Zwiastowanie Pańskie!] (Luleva 2002: 94)), choć na ogół ma on bezpośredni związek z podejmowanymi wówczas działaniami:

- 9 marca, przed wschodem słońca, kobiety wynoszą metalową pokrywkę do formy chlebowej z żarem, uderzają w nią szczypcami do węgli, żeby żar i popiół się posypały, po czym obchodzą tak trzy razy dom, mówiąc: Бягайте зъми и гущери, царската земя гори! [Uciekajcie węże i jaszczurki, carska ziemia płonie!] (Vasileva 1993b: 187);

- $\quad 25$ marca gospodyni wychodzi do ogrodu, niosąc żar ${ }^{5}$ i pokrzykując: Бежme

1 Por. ludowe wyobrażenia, według których węże żyją w ogromnej jaskini w dolnym świecie (Popov 2006a: 139).

2 Tabuistyczny zwrot do węża odwołujący się do tradycji biblijno-chrześcijańskiej.

3 Por. znany w bułgarskim folklorze model świata, w którym wąż występuje jako władca wodnego chaosu, a także mit o pływającej w wodzie ziemi podtrzymywanej przez węża (Benovska-Sabkova 1995: 16).

4 Formuła wykrzykiwana przez gospodynie, które w dniu 40 męczenników z Sebasty skaczą przez płonące śmieci - według ludowej etymologii praktyki charakterystyczne dla tego święta związane są z liczbą 40 (Vasileva 2006a: 285), stąd miejsce wypędzenia węży wyznaczone miarą 40 kroków.

5 Por. miejsca, w których wierzy się, że węże i jaszczurki można zatrzymać, rozsypując wokół domu popiół z paleniska (Vasileva 1993b: 187). 
зъми и гущери, че въ огън гони! [Uciekajcie węże, jaszczurki, bo ogień was goni!] (Vasileva 1974: 325).

W obu przypadkach zarówno tekst rytualny, jak i werbalny obrzędu wypędzenia koreluje z szeroko rozpowszechnionym w Bułgarii wierzeniem, według którego 9 marca słońce zwraca się ku latu i wbija w ziemię 140 lub 40 rozpalonych rożen, które ją ogrzewają (Vasileva 2006a: 285)ํ.

Dla części formuł charakterystycznym motywem jest przywołanie postaci ze świata mitycznego (najczęściej świętego lub personifikacji święta). Zapowiedź jej nadejścia, a zwłaszcza tego, co zrobi, ma skutecznie odstraszać pojawiające się wiosną węże, jaszczurki (i inne istoty chtoniczne)². Dlatego też 1 marca gospodyni obchodzi płonące śmieci, bije w dzwonki i ostrzega: Бягайте, змии и гущери, че иде Баба Марта, с огън и пламък ще ви изгори! [Uciekajcie węże i jaszczurki, bo Baba Marta nadchodzi, ogniem i płomieniem was spali!] (Grebenarova 1996: 329). Tego samego dnia dzieci, hałasując i ganiając wokół podwórza, nawołują: Бягайте, змии и гущери, че Баба Марта иде с калъчката да ва сече [Uciekajcie, węże i jaszczurki, bo Baba Marta nadchodzi, szablą siec was będzie] (Stamenova 1986: 264). Podobną formułę słowną wypowiadają kobiety, gdy zapalają śmieci przed progiem domu, a potem trzykrotnie go obchodzą od prawa do lewa, uderzając z całych sił w blachy: Бягайте змии, гущери и поганци, че баба Марта иде с железния топуз и желязната патеричка и където удари, син сок пуска! [Uciekajcie, węże i jaszczurki, bo Baba Marta nadchodzi z żelaznym buzdyganem i żelazna kulą, a gdy uderza, wypuszcza niebieski sok!] (Popov 1994: 101).

Nie inaczej jest 25 marca - w dniu, w którym, jak się wierzy, przebudzone gady opuszczają swoje legowiska ${ }^{3}$. Tym razem zagrożeniem dla nich ma być mityczny Błagowec (personifikacja dnia Zwiastowania Pańskiego):

- Бягайте, змии, гущери, бии, Благовец иде! [Uciekajcie, węże, jaszczurki, pchty, bо Błagowec ${ }^{4}$ nadchodzi!] - nawołują dzieci skaczące przy rozpalonym pod drzwiami ogniu (Drazheva 1980: 440);

- Бягайте, змии, благовец ша ва затисне! [Uciekajcie, węże, błagowec was

1 Szerzej o obrzędowości wypędzania gadów, a zwłaszcza roli, jaką odgrywają w niej czynności i przedmioty związane z ogniem, zob. Luleva 2002: 93-106.

2 W formułach węże najczęściej współwystępują z jaszczurkami, rzadziej z insektami lub gryzoniami.

3 Por. wierzenie, według którego w dniu poświęconym 40 męczennikom z Sebasty Bóg uderzył 4o patykami w ziemię, co obudziło węże, które obróciły się na drugą stronę. Wówczas pojawiło się na świecie po 40 zwierząt z wszystkich gatunków, a w dniu Zwiastowania Pańskiego - cała reszta. W innej wersji wierzenia 9 marca węże obracają się na drugą stronę, a wychodzą ze swoich kryjówek 25 marca (Vasileva 1985: 215).

$4 \mathrm{~W}$ przekładzie formuł z mityczną postacią jako personifikacją święta Zwiastowania Pańskiego zachowano bułgarską formę urobioną na podobieństwo nazw nosicieli cech, podając ją w transkrypcji. 
przygniecie!] - wołają, uderzając w blachy i chodząc wokół domu, po podwórzu i ogrodzie (Vasileva 1974: 325).

Podobnie jak Baba Marta jest on uzbrojony w żelazny atrybut ${ }^{1}$ : Бягайте, змии, смоци и г гущери, че Благовец ще ви удари с железния топуз! [Uciekajcie, węże, połozy i jaszczurki, bo Błagowec uderzy was żelaznym buzdyganem!] - wołają gospodynie, gdy robiąc hałas, trzykrotnie obchodzą swoje domy (Grebenarova 1996: 331).

W jednej z formuł postrachem dla węży i jaszczurek ma być chłopski car, przybywający w dniu Zwiastowania Pańskiego: Бягайте, зъми и гущери, днеска е Благовец! Иде цар цървулан, ша ва муши в миши дупки, ша ва навре в кози рог, ша ва сече мира по мupa [Uciekajcie węże i jaszczurki! Dzisiaj jest dzień Zwiastowania! Przychodzi car w kierpcach, wepcha was do mysiej dziury, zapędzi was w kozi róg, będzie was siec kawałek po kawałku] (Stamenova 1986: 265). Zagrożenie czyha na nie także ze strony nadchodzących w tym czasie Tatarów: Бежте, змии, гущери, утре е Благовец. Идат татаре, да ви мерат с кантаре [Uciekajcie węże i jaszczurki, jutro jest Dzień Zwiastowania Pańskiego. Idq Tatarzy, będq was ważyć na wagach] - wołają w wigilię święta dzieci, kobiety lub jedni i drudzy, gdy obchodzą obejście, uderzając przy tym czymś żelaznym (Vasileva 1993a: 248).

W ostatnie marcowe święto Bułgarzy straszą też bocianem, którego w kulturze ludowej uważa się za świętego ptaka i obrońcę oczyszczającego ziemię z gadów oraz innego plugastwa3: Бежте, зъми и гущери, че идат щръкелите! [Uciekajcie, węże i jaszczurki, bo nadciągają bociany!] (Gura \& Strahov 1995: 96).

Poza rytualnym wypędzaniem istot chtonicznych praktykuje się ich rytualne unieszkodliwianie. Stąd poświadczone w materiale czynności oparte na magii naśladowczej oraz

1 Por. też formułę wypędzenia wypowiadaną 1 maja, odnoszącą się do uzbrojonego (choć nie zostało to wyrażone wprost) proroka Jeremiasza: Бягайте змии и лошотии, оти ютре е Еремия / Еремия ке ви сечи, ке ви печи [Uciekajcie węże i wszelkie zło, bo jutro jest Jeremiasza / Jeremiasz będzie was siec, będzie was piec] (Luleva 2002: 96).

$2 \mathrm{~W}$ formułach wypędzenia gadów poza hiperonimem змии poświadczony został hiponim cмou̧ - forma liczby mnogiej od rzeczownika смок w znaczeniu duży wąż typowy dla krajów bałkańskich (Coluber) (Slawski 1987: t. 2: 1013), w Polsce znany pod nazwą połoz kaspijski. Bułgarzy mają do niego (inaczej niż do pozostałych węży) jednoznacznie pozytywny stosunek. Według wierzeń tylko on może chronić miedze na polach i w winnicach, uważa się go też za władcę żywiołów i zjawisk atmosferycznych, opiekuna miejsc sąsiadujących z granicą między tym i tamtym światem (Benovska-Sabkova 1995: 43-44). Mimo to bywa obiektem rytualnego wypędzenia, a w towarzyszących mu formułach werbalnych nierzadko pojawia się w parze z wężami.

3 Por. bułgarską legendę o człowieku wracającym z pielgrzymki do Ziemi Świętej, któremu Bóg dał do niesienia wielką skrzynię, uprzedzając przy tym, by jej nie otwierał. Gdy ten, wiedziony ciekawością, otworzył skrzynię, wyszły z niej wszystkie gady i płazy świata. Za karę Bóg zamienił go w bociana i obiecał, że przywróci mu ludzką postać, gdy ten oczyści ziemię z węży, jaszczurek i żab (Popov 20o6b: 357). 
towarzyszące im krótkie dialogi. I tak np. na św. Tryfona mażąc z zamkniętymi oczami palenisko i kąty w izbie, dziewczyna odpowiada na pytanie kogoś z rodziny:

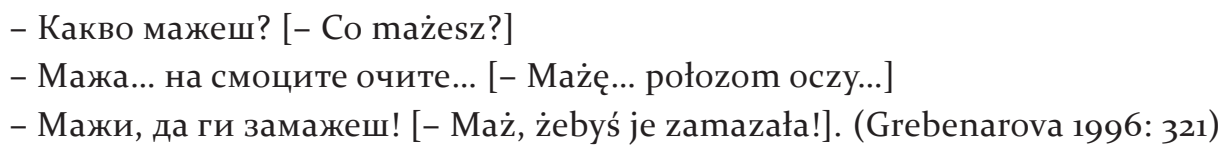

Wraz ze zmianą charakteru czynności (gdy w poniedziałek, w tygodniu poprzedzającym dzień św. Teodora gospodyni wrzuca szmaty do płonących śmieci) pytania i odpowiedzi ulegają modyfikacji:

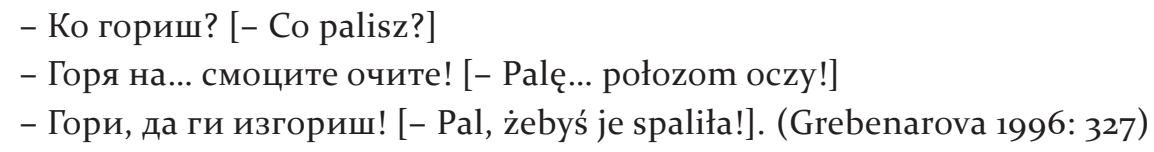

Gdzieniegdzie 1 marca starsza kobieta zawiązuje na czerwonej nitce supły, a ktoś pyta ją trzykrotnie, co robi, na co ta odpowiada: Завързвам на змиите и смоците очите [Zawiq̨uję wężom i połozom oczy] (Stamenova 1986: 264).

Symboliczne zamazywanie, palenie i zawiq̨zywanie oczu ma sprawić, by latem węże nie widziały ludzi¹, a ludzie ich (zamknięte oczy mażącego), by nie doszło do naruszenia zasady bycia nawzajem niewidzialnymi, świadczącej o rozdzieleniu tego i tamtego świata (Benovska-Sabkova 1995: 97).

\section{DRAPIEŻNIKI I GRYZONIE}

Podejmowanej na wiosnę ochronie przed drapieżnikami (wilkami) i gryzoniami (zwłaszcza myszami) w główniej mierze służą działania o charakterze apotropeicznym, sprowadzające się do przestrzegania szeregu tradycyjnych zakazów, z których jedne mają uzasadnienie w warstwie wierzeniowej, podczas gdy inne odwołują się do zasady podobne czyni podobne. W pierwszym dniu lutego nie wyrzuca się więc popiołu i śmieci, bo według wierzeń, jeśli je obliże wilczyca, zajdzie w ciążę (Popov 1999: 305) 3. Ponieważ może to nastąpić także po spróbowaniu przez nią mięsa człowieka ubranego w rzeczy wykonane podczas tzw. wilczych

\footnotetext{
1 Por. miejsca, w których 1 marca, mając przymrużone oczy, zawiązuje się dzieciom martenicę (splecione dwie wełniane nitki - białą i czerwoną), żeby węże były latem ślepe (Georgieva 1993: 64).

2 Drapieżniki: Трифоновден, Богородица / Bogurodzica (2 II), Симеоновден / dzień św. Symeona (3 II), Баба Марта; gryzonie: Трифоновден, Богородица, Симеоновден, Св. Четиридесет мъченици, Благовещение, Сирни заговезни, Тодорова неделя (poniedziałek).

3 Por. też owczarzy, którzy, gdy rozpalą w lesie ogień, zakopują w ziemi węgle, by chronić stado przed wilkami (Popov 1999: 305).
} 
świąt (Georgieva 1993: 55), zabrania się w tych dniach szycia, robienia na drutach (Popov 1994: 101-102), a gdzieniegdzie nawet dotykania wełny (Popov 1999: 305) lub nici (Popov 1994: 101). W niektórych rejonach nie wolno prać i myć się, żeby wilkom nie pieniły się pyski i nie szukały okazji do napaści na ludzi oraz ich dobytek (Vasileva 2006b: 68). Podobny skutek ma przynieść przestrzeganie zakazu pracy z przedmiotami, które otwierają się na podobieństwo wilczego pyska lub przywołują skojarzenia z jego ostrymi zębami - nie można kroić, szyć, robić na drutach, rąbać drewna (Popov 1994: 101-102). Te same ograniczenia mają chronić przed szkodami, jakie w gospodarstwie wyrządzają gryzonie - да не косяm мишките с острите си зъби дрехи и посевити [żeby myszy nie gryzły swoimi ostrymi zębami ubrań i posiewów] (Popov 1994: 96).

W materiale zostały także poświadczone magiczne działania symbolicznie zamykające wilcze pyski i oczy, takie jak zszywanie przedniej i tylnej poły spódnicy (Popov 1994: 102; Popov 1999: 305), związywanie nitką nożyc czy zawiązywanie łańcucha zawieszonego nad paleniskiem (Popov 1999: 305) ${ }^{1}$. Wykonaniu niektórych z nich towarzyszy, powtarzany trzykrotnie, rytualny dialog:

- Какво заключваш? [- Co zamykasz?] - pytają gospodynię, która zamyka kłódkę na wiszącym nad paleniskiem łańcuchu.

- На вълка устата заключвам. [- Wilkowi pysk zamykam.] - odpowiada i siada na podłodze, by zszyć poły swojej koszuli.

I znów pada pytanie:

- Какво шиеш? [- Co szyjesz?]

- На вълка устата, очите, ушите - да не яде овцете [- Wilkowi pysk, oczy, uszy - żeby nie jadł owiec.] (Tolstoy 1993: 90) ${ }^{2}$

W odniesieniu do wilka w tego typu magicznych zachowaniach bułgarska badaczka, Ana Łulewa, dostrzega analogię między jego symbolicznym zawiązaniem w okresach, które w tradycji ludowej znane są jako wilcze wesele (wilcza ruja), a zawiązaniem nowożeńca³.

1 Por. analogiczne symboliczne zawiq̨zywanie wilkom pysków, zasłanianie im oczu, gdy zgubi się jakieś zwierzę ze stada (Georgieva 1993: 55).

2 Ze względu na słabo poświadczony w ekscerpowanych źródłach etnograficznych materiał folklorystyczny, $\mathrm{w}$ tekście przytoczony został dialog towarzyszący analogicznym działaniom magicznym podejmowanym podczas jesiennych wilczych dni.

3 Por. alegoryczną formułę wypowiadaną podczas bułgarskich swatów, w której pretendent do ręki dziewczyny, potencjalny przyszły nowożeniec, zostaje przedstawiony jako młody wilczek: Вий имате млада теличка, пък ние младо вълче [Wy macie młodą jałóweczkę, a my młodego wilczka.] (Gura 1997: 126). 
W planie mitologicznym zdolność wilka do gryzienia miałaby więc decydować o jego zdolności do zapładniania ${ }^{1}$. Zawiq̨zanie pozbawia go obu tych właściwości, a wraz z oślepieniem (zaszyciem oczu) oznacza zabicie w tym świecie i odesłanie do tamtego świata (Luleva 2002: 128-129). Tym samym dochodzi tu, podobnie jak w obrzędach wypędzenia insektów i gadów, do oczyszczenia (w planie symbolicznym) przestrzeni kulturowej z elementu chtonicznego i typowego dla okresu przejścia rozdzielenia obu światów.

Ten sam rezultat przynosi magiczne zamazywanie lub palenie oczu myszom²:

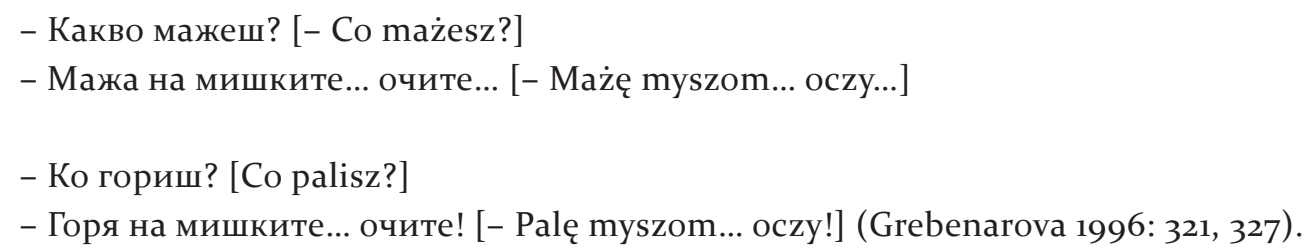

Reasumując, bułgarska obrzędowość służąca ochronie przed aktywizującymi się wiosną przedstawicielami sił chtonicznych, zasadza się na czynnościach katarktycznych (porządki w domu / obejściu, skakanie przez płonące śmieci lub specjalnie rozpalone ognie, rzucanie płonących pochodni, wypuszczanie ognistych strzał, okadzanie dymem z żaru) i apotropeicznych (robienie hałasu, przestrzeganie zakazów związanych z wykonywaniem codziennych prac gospodarskich, magiczne unieszkodliwianie).

Oczyszczenie przestrzeni kulturowej z insektów, gadów, drapieżników i gryzoni w planie symbolicznym oznacza ich powrót do tamtego świata. Na poziomie tekstu rytualnego i werbalnego obrzędu wypędzenia insektów oraz gadów ma on wymiar przestrzenny i personalny. Z jednej strony obiekt czynności jest odsyłany do miejsc, które odpowiadają ludowym wyobrażeniom o tamtym świecie lub granicy między tym i tamtym światem, z drugiej - do osób, postaci mitycznych, którym przypisuje się status obcych bądź mediatorów między obu światami. Temu samemu celowi - rozdzieleniu tego i tamtego świata służy magiczne unieszkodliwienie gadów, drapieżników i gryzoni (symboliczne zamknięcie ich pysków, oczu).

\footnotetext{
1 Por. erotyczną symbolikę, którą bywa obciążany wilk napadający na bydło i zagryzający swoją zdobycz (ugryzienie wilka - akt seksualny, wilczy ząb - penis) (Gura 1997: 127).

2 W formułach słownych obiektem obu czynności są jednocześnie myszy i węże: - Мажа на мишките и на смоците очите... [- Mażę myszom i połozom осzу...]; - Горя на мишките и смоците очите! [- Palę myszom i połozom oczy!] (Grebenarova 1996: 321, 327).
} 
Towarzyszące czynnościom rytualnym teksty folkloru to mniej lub bardziej rozbudowane formuły werbalne (obrzędy wypędzenia) i krótkie dialogi (magiczne unieszkodliwienie). Dla pierwszych znamienne jest wyraźne przeciwstawienie sobie dwóch światów i przynależnych im postaci (człowiek, postać mityczna, święto - ten świat versus pchły, wszy, węże, jaszczurki - tamten świat). Drugie stanowią swoisty komentarz do podejmowanych działań.

Czynności apotropeiczne to przede wszystkim obowiązujące w określone dni świąteczne zakazy ukierunkowane na ochronę przed konsekwencjami kontaktu z siłami chtonicznymi. Większość z nich jest motywowana warstwą wierzeniową (zakaz wyrzucania popiołu i węgli zapładniających wilki) lub opiera się na zasadzie podobne czyni podobne (zawiązywanie nożyc, zakaz dotykania ostrych, tnących przedmiotów, nitek).

\section{REFERENCES}

Agapkina 2002: Agapkina, Tatyana A. Mythological-Poetic Basis of the Slavic Folk Calendar. The Spring-Summer Cycle. Moscow: Indrik, 2002. [In Russian: Агапкина, Татьяна A. Мифопоэтические основы славянского народного календаря. Весенне-летний цикл. Москва: Индрик, 2002.]

Bayburin 1990: Bayburin, Albert K. "Ritual: Own and Foreign." In Putilov, Boris N., ed. Folklore and Ethnography. Problems of Reconstructing the Facts of Traditional Culture: 3-17. Leningrad: Nauka, 1990. [In Russian: Байбурин, Альберт К. „Ритуал: свое и чужое.“ В: Путилов, Борис Н., ред. Фольклор и этнография. Проблемы рекострукции фактов традиционной культуры: 3-17. Ленинград: Наука, 199о.]

Belova 1999: Belova, Olga V. “Goat.” In Tolstoy, Nikita I., ed. The Slavic Antiquities. Ethnolinguistic Dictionary. Vol. 2: 522-524. Moscow: Institute for Slavic Studies of the Russian Academy of Sciences, International Relationships Publishing House, 1999. [In Russian: Белова, Ольга В. „Коза.“ В: Толстой, Никита И., ред. Славянские древности. Этнолингвистический словарь. Т. 2: 522-524. Москва: Институт славяноведения РАН, Издательство „Международные отношения", 1999.]

Belova 2009: Belova, Olga V. "Pig." In Tolstoy, Nikita I., ed. The Slavic Antiquities. Ethnolinguistic Dictionary. Vol. 4: 573-576. Moscow: Institute for Slavic Studies of the Russian Academy of Sciences, International Relationships Publishing House, 2009. [In Russian: Белова, Ольга В. „Свинья.“ В: Толстой, Никита И., ред. Славянские древности. Этнолингвистический словарь. Т. 4: 573-576. Москва: Институт славяноведения РАН, Издательство „Международные отношения", 2009.]

Belova 2012: Belova, Olga V. "Black Color." In Tolstoy, Nikita I., ed. The Slavic Antiquities. Ethnolinguistic Dictionary. Vol. 5: 513-518. Moscow: Institute for Slavic Studies of the Russian Academy of Sciences, International Relationships Publishing House, 2012. [In Russian: Белова, Ольга В. „Черный цвет.“ В: Толстой, Никита И., ред. Славянские древности. 
Этнолингвистический словарь. Т. 5: 513-518. Москва: Институт славяноведения РАН, Издательство „Международные отношения”, 2012.]

Benovska-Sabkova 1995: Benovska-Sabkova, Milena. The Dragon in Bulgarian Folklore. Sofia: Professor Marin Drinov Publishing House of BAS, 1995. [In Bulgarian: Беновска-Събкова, Милена. Змеят в българския фолклор. София: Проф. Марин Дринов, 1995.]

Drazheva 1980: Drazheva, Rayna. "Calendar Feasts and Rituals." In Hadzhinikolov, Veselin \& Veleva, Mariya \& Georgiev, Georgi \& Todorov, Delcho, eds. The Region of Pirin. Ethnographic, Folklore and Linguistic Studies: 422-456. Sofia: BAS, 1980. [In Bulgarian: Дражева, Райна. „Календарни празници и обичаи." В: Хаджиниколов, Веселин \& Велева, Мария \& Георгиев, Георги \& Тодоров, Делчо, ред. Пирински край. Етнографски, фолклорни и езикови проучвания: 422-456. София: БАН, 1980.]

Georgieva 1993: Georgieva, Ivanichka. Bulgarian Folk Mythology. Sofia: Nauka i izkustvo, 1993. [In Bulgarian: Георгиева, Иваничка. Българска народна митология. София: Наука и изкуство, 1993.]

Grebenarova 1996: Grebenarova, Slavka. “Calendar Customs and Rituals.” In Tcherkezova, Marina \& Popov, Rachko \& Raychevski, Stoyan, eds. Strandzha. Material and Spiritual Culture: 305-350. Sofia: Professor Marin Drinov Publishing House of BAS, 1996. [In Bulgarian: Гребенарова, Славка. „Календарни обичаи и обреди.” В: Черкезова, Марина \& Попов, Рачко \& Райчевски, Стоян, ред. Странджа. Материална и духовна култура: 305-350. София: Проф. Марин Дринов, 1996.]

Gura 1997: Gura, Aleksandr V. Symbolism of Animals in the Slavic Folk Tradition. Moscow: Indrik, 1997. [In Russian: Гура, Александр В. Символика животных в славянской народной традиции. Москва: Индрик, 1997.]

Gura \& Strahov 1995: Gura, Aleksandr V. \& Strahov, Aleksandr V. "Stork." In Tolstoy, Nikita I., ed. The Slavic Antiquities. Ethnolinguistic Dictionary. Vol. 1: 96-10o. Moscow: Institute for Slavic Studies of the Russian Academy of Sciences, International Relationships Publishing House, 1995. [In Russian: Гура, Александр В. \& Страхов, Александр В. „Аист.“ В: Толстой, Никита И., ред. Славянские древности. Этнолингвистический словарь. Т. 1: 96-10о. Москва: Институт славяноведения РАН, Издательство „Международные отношения”, 1995.]

Luleva 2002: Luleva, Ana. The World of Things in Rural Bulgarian House. Sofia: Professor Marin Drinov Publishing House of BAS, 2002. [In Bulgarian: Лулева, Ана. Светът на вещите в традиционния български дом. София: Проф. Марин Дринов, 20о2.]

Manova 2016: Manova, Tsvetana. "Stranger." In Georgiev, Mincho, ed. Mythology of the Human Body. Anthropological Dictionary: 444-447. Sofia: Professor Marin Drinov Publishing House of BAS \& Sofia University Press, 2016. [In Bulgarian: Манова, Цветана. „Чужденец.“ В: Георгиев, Минчо, ред. Митология на човешкото тяло. Антропологичен речник: 444-447. София: Проф. Марин Дринов \& УИ Св. Климент Охридски, 2016.]

Mikov 1985: Mikov, Lyubomir. Rituals of 1st March. Sofia: Septemvri, 1985. [In Bulgarian: Миков, Любомир. Първомартенска обредност. София: Септември, 1985.]

Mleczko 2015: Mleczko, Joanna. "The Opposition Old - Young and Old - New in Bulgarian Folklore, Baba Marta’s Day." In Petreska, Vesna \& Rekas, Joanna, eds. Balkan Folklore as an Intercultural Code. Vol. 2: 191-203. Skopje-Poznan: Marko Cepenkov Institute of Folklore, Institute of Slavonic Philology at Adam Mickiewicz University, 2015. [In Polish: Mleczko, Joanna. „Opozycja stare młode, stare - nowe w bułgarskiej obrzędowości związanej z Babą Martą.” W: Petreska, Vesna 
\& Rękas, Joanna, red. Bałkański folklor jako kod interkulturowy. T. 2: 191-203. Skopje-Poznań: Instytut Folkloru im. Marka Cepenkova, Instytut Filologii Słowiańskiej Uniwersytetu im. Adama Mickiewicza, 2015.]

Mleczko 2018: Mleczko, Joanna. Traditional Bulgarian Wedding Ceremony. An Ethno-linguistic Study. Katowice: University of Silesia Press, 2018. [In Polish: Mleczko, Joanna. Tradycyjny bułgarski obrzęd weselny. Studium etnolingwistyczne. Katowice: Wydawnictwo Uniwersytetu Śląskiego, 2018.]

Plotnikova 1999: Plotnikova, Anna A. "Yard." In Tolstoy, Nikita I., ed. The Slavic Antiquities. Ethnolinguistic Dictionary. Vol. 2: 31-33. Moscow: Mezddunarodnyye otnosheniya, 1999. [In Russian: Плотникова, Анна А. „Двор.“ В: Толстой, Никита И., ред. Славянские древности. Этнолингвистический словарь. Т. 2: 31-33. Москва: Международные отношения, 1999.]

Popov 1994: Popov, Rachko. "Calendar Feasts and Rituals." In Grebenarova, Slavka \& Popov, Rachko, eds. Rhodopes. Traditional Folk Spiritual and Social-Normative Culture: 82-117. Sofia: Ethnographic Institute with a Museum of BAS, 1994. [In Bulgarian: Попов, Рачко. „Календарни празници и обичаи." В: Гребенарова, Славка \& Попов, Рачко, ред. Родопи. Традиционна народна духовна и социалнонормативна култура: 82-117. София: Етнографски институт с музей при БАН, 1994.]

Popov 1999: Popov, Rachko. “Calendar Feasts and Rituals.” In Popov, Rachko \& Mihaylova, Ganka, eds. Lovech Region. Material and Spiritual Culture: 293-320. Sofia: Professor Marin Drinov Publishing House of BAS, 1999. [In Bulgarian: Попов, Рачко. „Календарни празници и обичаи.” В: Попов, Рачко \& Михайлова, Ганка, ред. Ловешки край. Материална и духовна култура: 293-320. София: Проф. Марин Дринов, 1999.]

Popov 2006a: Popov, Rachko. “Snake.” In Stoynev, Anani, ed. Bulgarian Mythology. Encyclopedic Dictionary: 139-140. Sofia: Zahari Stoyanov, 2006. [In Bulgarian: Попов, Рачко. „Змия.“ В: Стойнев, Анани, ред. Българска митология. Енциклопедичен речник: 139-140. София: Захари Стоянов, 2006.]

Popov 20o6b: Popov, Rachko. “Stork.” In Stoynev, Anani, ed. Bulgarian Mythology. Encyclopedic Dictionary: 357. Sofia: Zahari Stoyanov, 2006. [In Bulgarian: Попов, Рачко. „Щъркел.“ В: Стойнев, Анани, ред. Българска митология. Енциклопедичен речник: 357. София: Захари Стоянов, 2006.]

Raycheva-Ganeva 2002: Raycheva-Ganeva, Valentina. "Calendar Feasts and Rituals." In Popov, Rachko \& Grebenarova, Slavka, eds. Sakar. Ethnographic, Folklore and Linguistic Study: 324-371. Sofia: Professor Marin Drinov Publishing House of BAS, 2002. [In Bulgarian: Райчева-Ганева, Валентина. „Календарни празници и обичаи.” В: Попов, Рачко \& Гребенарова, Славка, ред. Сакар. Етнографско, фолклорно и езиково изследване: 324-371. София: Проф. Марин Дринов, 2002.]

Slawski 1987: Slawski, Franciszek: Bulgarian-Polish Concise Dictionary. Vol. 1-2. Warsaw: Wiedza Powszechna, 1987. [In Polish: Sławski, Franciszek. Podręczny słownik butgarsko-polski. T. 1-2. Warszawa: Wiedza Powszechna, 1987.]

Stamenova 1986: Stamenova, Zhivka. "Calendar Feasts and Rituals." In Mihaylova, Ganka \& Vasileva, Margarita \& Veleva, Mariya \& Primovski, Anastas, eds. Plovdiv Region. Ethnographic and Linguistic Studies: 244-283. Sofia: BAS, 1986. [In Bulgarian: Стаменова, Живка. „Календарни празници и обичаи." В: Михайлова, Ганка \& Василева, Маргарита \& Велева, Мария \& Примовски, Анастас, ред. Пловдивски край. Етнографски и езикови проучвания: 244-283. София: БАН, 1986.] 
Tolstoy 1990: Tolstoy, Nikita I. "South Slavic Todoritsa / Saint Theodore's Day. Rite, Its Structure and Geography." In Grintser, Nikolay P. \& Zlydneva, Nataliya V. \& Toporov, Vladimir N., eds. Balkan Readings. Symposium on Text Structure. Thesis and Materials: 101-109. Moscow: Institute for Slavic and Balkan Studies of the USSR Academy of Sciences, 199o. [In Russian: Толстой, Никита И. „Южнославянские Тодорица / Тодоровден. Обряд, его структура и география.“ В: Гринцер, Николай П. \& Злыднева, Наталия В. \& Топоров, Владимир Н., ред. Балканские чтения. Симпозиум по структуре текста. Тезиси и материалы: 101-109. Москва: Институт славяноведения и балканистики АН СССР, 1990.]

Tolstoy 1993: Tolstoy, Nikita. "Once Again about the Slavic Ritual Dialogue." In Tolstoy, Nikita I. \& Tsivyan, Tatyana V., eds. Slavic and Balkan Linguistics. The Structure of Small Folklore Texts: 82-110. Moscow: Nauka, 1993. [In Russian: Толстой, Никита И. „Ещё раз о славянском ритуальном диалоге." В: Толстой, Никита И. \& Цивьян, Татьяна В., ред. Славянское и балканское языкознание. Структура малых фольклорных текстов: 82-11о. Москва: Наука, 1993.]

Tolstoy 1995: Tolstoy, Nikita I. "From the Grammar of Slavic Rites." In Tolstoy, Nikita I. Language and Folk Culture. Sketches from Slavic Mythology and Ethnolinguistics: 63-77. Moscow: Indrik, 1995. [In Russian: Толстой, Никита И. „Из грамматики славянских обрядов.“ В: Толстой, Никита И. Язык и народная культура. Очерки по славянской мифологии и этнолингвистике: 63-77. Москва: Индрик, 1995.]

Vasileva 1974: Vasileva, Margarita. "Calendar Feasts and Rituals." In Todorov, Delcho \& Genchev, Stoyan \& Krasteva, Gina \& Mladenov, Maksim, eds. Dobrudja. Ethnographic, Folklore and Linguistic Studies: 301-344. Sofia: BAS, 1974. [In Bulgarian: Василева, Маргарита. „Календарни празници и обичаи." В: Тодоров, Делчо \& Генчев, Стоян \& Кръстева, Гина \& Младенов, Максим, ред. Добруджа. Етнографски, фолклорни и езикови проучвания: 301-344. София: БАН, 1974.]

Vasileva 1985: Vasileva, Margarita. "Calendar Feasts and Rituals." In Todorov, Delcho \& Mihaylova, Ganka \& Vasileva, Margarita \& Mladenov, Maksim, eds. Kapantsi. Life and Culture of the Ancient Bulgarian Population in Northeastern Bulgaria. Ethnographic and Linguistic Research: 200-235. Sofia: BAS, 1985. [In Bulgarian: Василева, Маргарита. „Календарни празници и обичаи.” B: Тодоров, Делчо \& Михайлова, Ганка \& Василева, Маргарита \& Младенов, Максим, ред. Капанци. Бит и култура на старото българско население в Североизточна България. Етнографски и езикови проучвания: 200-235. София: БАН, 1985.]

Vasileva 1993a: Vasileva, Margarita. "Calendar Feasts and Rituals." In Genchev, Stoyan \& Georgieva, Bagra, eds. The Region of Sofia. Ethnographic and Linguistic Studies: 234-26o. Sofia: BAS, 1993. [In Bulgarian: Василева, Маргарита. „Календарни празници и обичаи.” В: Генчев, Стоян \& Георгиева, Багра, ред. Софийски край. Етнографски и езикови проучвания: 234-260. София: БАН, 1993.]

Vasileva 1993b: Vasileva, Margarita. "Traditional Calendar and Family Customs of the Karnobat Region." In Todorov, Delcho, ed. History and Culture of the Karnobat Region: 163-234. Sofia: BAS, 1993. [In Bulgarian: Василева, Маргарита. „Традиционни календарни и семейни обичаи в Карнобатско." В: Тодоров, Делчо, ред. История и култура на Карнобатския край: 163-234. София: БАН, 1993.]

Vasileva 2oo6a: Vasileva, Margarita. “Forty Martyrs of Sebaste." In Stoynev, Anani, ed. Bulgarian Mythology. Encyclopedic Dictionary: 285-286. Sofia: Zahari Stoyanov, 2006. [In Bulgarian: 
Василева, Маргарита. „Св. Четирисе.“ В: Стойнев, Анани, ред. Българска митология. Енциклопедичен речник: 285-286. София: Захари Стоянов, 2006.]

Vasileva 2oo6b: Vasileva, Margarita. "Wolf Feasts." In Stoynev, Anani, ed. Bulgarian Mythology. Encyclopedic Dictionary: 68-69. Sofia: Zahari Stoyanov, 2006. [In Bulgarian: Василева, Маргарита. „Вълчи празници.“ В: Стойнев, Анани, ред. Българска митология. Енциклопедичен речник: 68-69. София: Захари Стоянов, 2006.]

Vinogradova \& Tolstaya 1993: Vinogradova, Lyudmila N. \& Tolstaya, Svetlana M. "Symbolic Language of Things: The Broom in Slavic Rites and Beliefs." In Tolstaya, Svetlana M. \& Sedakova, Irina A., eds. Balkan Readings. Symbolic Language of Traditional Culture: 3-36. Moscow: Institute for Slavic and Balkan Studies of the USSR Academy of Sciences, 1993. [In Russian: Виноградова, Людмила \& Толстая, Светлана. „Символический язык вещей: веник (метла) в славянских обрядах и верованиях." В: Толстая, Светлана \& Седакова, Ирина, ред. Балканские чтения. Символический язык традиционной культуры: 3-36. Москва: Институт славяноведения и балканистики АН СССР, 1993.] 